Chem., Process Des. Dev., 17, 161 (1978).

2) Overturf, B. W., G. V. Reklaitis and J. M. Woods: Ind. Eng. Chem., Process Des. Dev., 17, 166 (1978).

3) Reklaitis, G. V.: Proceedings of PSE'82 (Technical sessions), 146 (1982).

4) Rippin, D. W. T.: Proceedings of PSE'82 (Keynote sessions),
263 (1982).

5) Smith, N. H. and D. F. Rudd: Chem. Eng. Sci., 19, 403 (1964).

6) Takamatsu, T., I. Hashimoto, S. Hasebe and M. O'shima: Proceedings of PSE'82 (Technical sessions), 158 (1982).

7) Thesen, A.: "Computer Methods in Operations Research," Academic Press, New York (1978).

\title{
A STUDY OF SEPARATION EFFICIENCY OF THE CONTINUOUS THERMAL DIFFUSION COLUMN WITH AN IMPERMEABLE BARRIER BETWEEN PLATES
}

\author{
SHAU-WeI TSAI AND HO-MING YEH \\ Department of Chemical Engineering, National Cheng Kung University, \\ Tainan, Taiwan, Republic of China
}

Key Words: Thermal Diffusion, Improved Column Design, Separation Efficiency, Optimal Barrier Positions, Back Mixing

\begin{abstract}
Properly installing an impermeable barrier between the plates of a continuous flat-plate thermal diffusion column may substantially increase the separation efficiency by reducing the remixing effect, while still preserving the cascading effect. Theoretical considerations show that when the column is designed with the best barrier position, maximum concentration of top product, minimum concentration of bottom product and maximum degree of separation are obtained simultaneously.
\end{abstract}

\section{Introduction}

Thermal diffusion is an unusual process which can be used to separate mixtures that are hard to separate by means of conventional methods such as distillation or extraction. It was the great achievement of Clusius and Dickel ${ }^{2)}$ to introduce the thermogravitational thermal diffusion column to make this separation process practical. The first complete presentation of the theory of the C-D column was given by Furry et $a l^{3)}$

A more detailed study of the mechanism of separation in the Clusius-Dickel column indicates that the convective currents actually have two conflicting effects: a desirable cascading effect and an undesirable remixing effect. The convective currents have a multistage effect which is necessary in securing high separation, and it is an essential feature of the Clusius-Dickel column. However, since the convective currents bring down the fluid at the top of the column, where it is rich in one component, to the bottom of the column, where it is rich in the other component, and vice versa, there is a remixing of the two components. It appears, therefore, that proper

Received May 31, 1986. Correspondence concerning this article should be addressed to S. W. Tsai. control of the convective strength might effectively suppress this undesirable remixing effect while still preserving the desirable cascading effect, and thereby lead to improved separation. Based on this concept, some improved columns have been reported in the literature, such as inclined columns, ${ }^{1,5)}$ wired columns, ${ }^{10,11)}$ inclined moving-wall columns, ${ }^{6,12)}$ rotary columns, ${ }^{7,13,17,18)}$ packed columns, ${ }^{4,14)}$ rotary wired columns ${ }^{15,16)}$ and permeable barrier columns. ${ }^{20-22)}$

Recently, Tsai and $\mathrm{Yeh}^{9}$ have developed a simple but effective batch-type thermal diffusion column in which an impermeable barrier is inserted between the plates for properly adjusting the convective strength. It is found that when the barrier is installed at the best position, considerable improvement in the degree of separation and product concentrations is obtained under fixed heat consumption. In general, a thermal diffusion column is designed for continuous operation. Therefore, it is the purpose of this work to extend the separation theory and investigate the separation efficiency of a barrier column under continuous operation.

\section{Column Theory}

1.1 The open column

Consider a continuous flat-plate thermogravi- 
tational thermal diffusion column filled with a binary mixture. The distance between the plates is $\left(\omega_{A}+\omega_{B}\right)$ Furry et $a l^{3)}$ have presented an equation which gives the separation for the column with top and bottom products withdrawn at the same rate from both ends, with the feed introduced at the center of the column, and for the case when the concentration in the column is everywhere between 0.3 to 0.7 weight fraction. At steady state, the degree of separation obtainable is

$$
\Delta_{o}=C_{t, o}-C_{b, o}=\frac{1}{2 \sigma^{\prime}}\left\{1-\exp \left[\frac{-\sigma^{\prime} L^{\prime}}{2\left(1+K_{d} / K_{c}\right)}\right]\right\}
$$

where the dimensionless column length and dimensionless product rate are defined as

$$
L^{\prime}=\frac{L H}{K_{c}}, \quad \sigma^{\prime}=\frac{\sigma}{H}
$$

The transport constants $H, K_{c}$ and $K_{d}$ in Eq. (2) are given by

$$
\begin{gathered}
H=\frac{\alpha \rho B \beta g(\Delta T)^{2}\left(\omega_{\mathrm{A}}+\omega_{\mathrm{B}}\right)^{3}}{6 ! \mu \widetilde{T}} \\
K_{c}=\frac{\rho \beta^{2} B g^{2}(\Delta T)^{2}\left(\omega_{\mathrm{A}}+\omega_{\mathrm{B}}\right)^{7}}{9 ! \mu^{2} D} \\
K_{d}=\rho D B\left(\omega_{\mathrm{A}}+\omega_{\mathrm{B}}\right)
\end{gathered}
$$

During the derivation of the equations above, all physical properties, defined in the Nomenclature section, are evaluated at the reference temperature

$$
\widetilde{T}=T_{m}=\left(T_{1}+T_{2}\right) / 2
$$

\subsection{An improved column}

Consider a continuous flat-plate thermal diffusion column with an impermeable barrier inserted between the plates. The barrier has a thickness $\delta$ comparable to the distance between the plates, $\left(\omega_{\mathrm{A}}+\omega_{\mathrm{B}}\right)$, as shown in Fig. 1. Feeds are introduced at the center of the column and the products are withdrawn from both ends for each section with the same flow rate. The use of a truly impermeable barrier, such as a metal sheet, has the effect of producing two open columns side-by-side, the two having equal heat fluxes and a common temperature at their junction. Since the two sides, sections A and B, are separated everywhere by a barrier permitting heat flow but no mass flow, each will operate independently, with no mass exchange, except for the shared temperature gradient. At steady state, the compositions in each section will therefore depend on the feed composition.

Following the same derivation as that performed by Furry et al. ${ }^{3)}$ we obtain the separation equations as follows.

1) For section $A$ on the cold side

$$
\Delta_{\mathrm{A}}=C_{t, \mathbf{A}}-C_{b, \mathrm{~A}}=\frac{H_{\mathrm{A}}}{2 \sigma_{\mathrm{A}}^{-}}\left\{1-\exp \left[\frac{-\sigma_{\mathrm{A}} L}{2\left(K_{c, \mathrm{~A}}+K_{d, \mathrm{~A}}\right)}\right]\right\}
$$

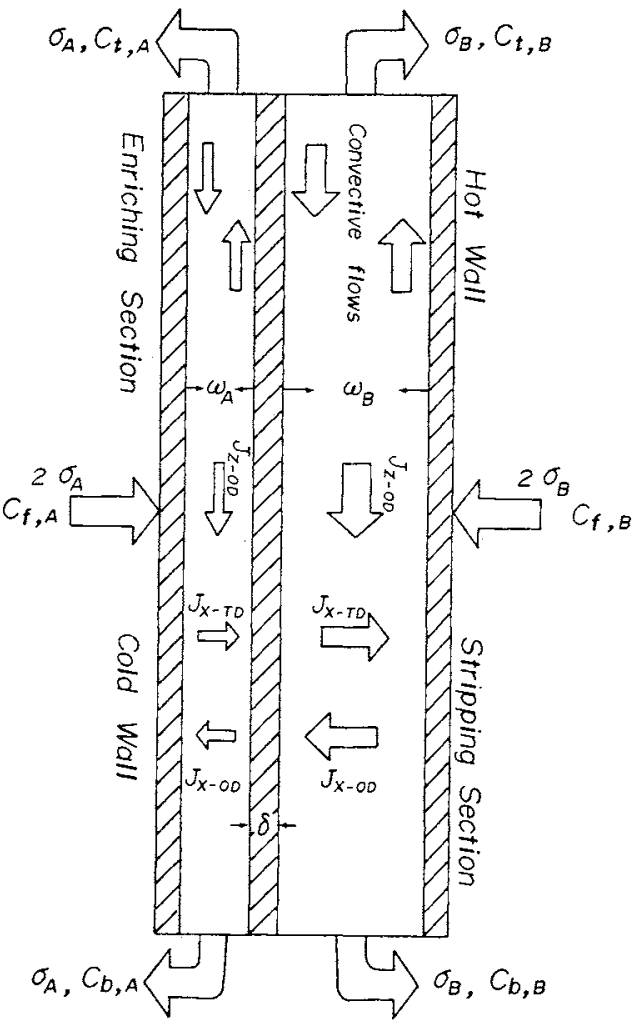

Fig. 1. Schematic diagram of a continuous thermal diffusion column with vertical impermeable barrier inserted between plates.

$$
\begin{aligned}
C_{t, \mathrm{~A}} & =C_{f, \mathrm{~A}}+\frac{\Delta_{\mathrm{A}}}{2} \\
C_{b, \mathrm{~A}} & =C_{f, \mathrm{~A}}-\frac{\Delta_{\mathrm{A}}}{2}
\end{aligned}
$$

where the transport constants are defined as

$$
\begin{aligned}
H_{\mathrm{A}} & =\frac{\alpha \rho B \beta g(\Delta T)_{\mathrm{A}}^{2} \omega_{\mathrm{A}}^{3}}{6 ! \mu \tilde{T}_{\mathrm{A}}} \\
K_{c, \mathrm{~A}} & =\frac{\rho \beta^{2} g^{2} B(\Delta T)_{\mathrm{A}}^{2} \omega_{\mathrm{A}}^{7}}{9 ! \mu^{2} D} \\
K_{d, \mathrm{~A}} & =\rho D B \omega_{\mathrm{A}}
\end{aligned}
$$

The physical properties in the equations above are evaluated at the reference temperature $\tilde{T}_{\mathrm{A}}$. The temperature difference and reference temperature for section A are easily found by assuming the thermal resistances between the plates in series. Hence, we obtain

$$
(\Delta T)_{\mathrm{A}}=\frac{\omega_{\mathrm{A}}(\Delta T)}{\omega_{\mathrm{A}}+\omega_{\mathrm{A}}+\delta\left(k / k_{1}\right)}
$$

and

$$
\widetilde{T}_{\mathrm{A}}=T_{1}+\frac{(\Delta T)_{\mathrm{A}}}{2}
$$

2) For section $B$ on the warm side All the equations have the same form as those for section $\mathrm{A}$, 
except that the subscript " $A$ " is replaced by " $B$ " and

$$
\begin{aligned}
(\Delta T)_{\mathrm{B}} & =\frac{\omega_{\mathrm{B}}(\Delta T)}{\omega_{\mathrm{A}}+\omega_{\mathrm{B}}+\delta\left(k / k_{1}\right)} \\
\widetilde{T}_{\mathrm{B}} & =T_{2}-\frac{(\Delta T)_{\mathrm{B}}}{2}
\end{aligned}
$$

3) For the whole column To compare the separation efficiency with that obtained in the ClusiusDickel column, we may let $C_{f, \mathrm{~A}}=C_{f, \mathrm{~B}}=C_{f}$ and $\sigma=\sigma_{\mathrm{A}}+\sigma_{\mathrm{B}}$. Moreover, the mass flow rate between two parallel walls under the same pressure drop is proportional to the cube of the distance between the plates, when only the forced convection is present. Accordingly, we have

$$
\begin{aligned}
& \sigma_{\mathrm{A}}=\sigma \omega_{\mathrm{A}}^{3} /\left(\omega_{\mathrm{A}}^{3}+\omega_{\mathrm{B}}^{3}\right) \\
& \sigma_{\mathrm{B}}=\sigma \omega_{\mathrm{B}}^{3} /\left(\omega_{\mathrm{A}}^{3}+\omega_{\mathrm{B}}^{3}\right)
\end{aligned}
$$

We may also define the average quantities of products as

$$
\begin{aligned}
& \Delta_{\mathrm{av}}=\left(\sigma_{\mathrm{A}} \Delta_{\mathrm{A}}+\sigma_{\mathrm{B}} \Delta_{\mathrm{B}}\right) / \sigma \\
& C_{t, \mathrm{av}}=\left(\sigma_{\mathrm{A}} C_{t, \mathrm{~A}}+\sigma_{\mathrm{B}} C_{t, \mathrm{~B}}\right) / \sigma \\
& C_{b, \mathrm{av}}=\left(\sigma_{\mathrm{A}} C_{b, \mathrm{~A}}+\sigma_{\mathrm{B}} C_{b, \mathrm{~B}}\right) / \sigma
\end{aligned}
$$

It is convenient to define the dimensionless groups as

$$
\begin{aligned}
& \pi_{1}=\delta /\left(\omega_{\mathrm{A}}+\omega_{\mathrm{B}}\right) \\
& \pi_{2}=k / k_{1} \\
& \pi_{3}=\omega_{\mathrm{B}} / \omega_{\mathrm{A}}
\end{aligned}
$$

If the temperature difference between the plates, i.e. $\Delta T$, is not large or the products of physical properties in the transport constants are not sensitive to the reference temperature, Eqs. (19) to (21) can be rearranged to give Eqs. (25) to (27) by use of Eqs. (2) to (18) and Eqs. (22) to (24).

$$
\begin{aligned}
& \Delta_{\mathrm{av}}=\left(\Delta_{\mathrm{A}}+\pi_{3}^{3} \Delta_{\mathrm{B}}\right) /\left(1+\pi_{3}^{3}\right) \\
& C_{t, \mathrm{av}}=C_{f}+\Delta_{\mathrm{av}} / 2 \\
& C_{b, \mathrm{av}}=C_{f}-\Delta_{\mathrm{av}} / 2
\end{aligned}
$$

in which

$$
\begin{aligned}
\Delta_{\mathrm{A}}= & {\left[\frac{\left(1+\pi_{3}^{3}\right)}{2 \sigma^{\prime}\left(1+\pi_{3}\right)^{5}\left(1+\pi_{1} \pi_{2}\right)^{2}}\right]\left[1-\exp \left\{\left[\frac{-\sigma^{\prime} L^{\prime}}{2}\right]\right.\right.} \\
& \left.\left.\times\left[\frac{\left(1+\pi_{3}\right)^{9}\left(1+\pi_{1} \pi_{2}\right)^{2}}{\left(1+\pi_{3}^{3}\right)\left[1+\left(1+\pi_{3}\right)^{8}\left(1+\pi_{1} \pi_{2}\right)^{2}\left(K_{d} / K_{c}\right)\right]}\right]\right\}\right]
\end{aligned}
$$

$$
\begin{aligned}
\Delta_{\mathrm{B}}= & {\left[\frac{\left(1+\pi_{3}^{3}\right) \pi_{3}^{2}}{2 \sigma^{\prime}\left(1+\pi_{3}\right)^{5}\left(1+\pi_{1} \pi_{2}\right)^{2}}\right]\left[1-\exp \left\{\left[\frac{-\sigma^{\prime} L^{\prime}}{2}\right]\right.\right.} \\
& \left.\left.\times\left[\frac{\left(1+\pi_{3}\right)^{9}\left(1+\pi_{1} \pi_{2}\right)^{2} \pi_{3}^{2}}{\left(1+\pi_{3}^{3}\right)\left[\pi_{3}^{8}+\left(1+\pi_{3}\right)^{8}\left(1+\pi_{1} \pi_{2}\right)^{2}\left(K_{d} / K_{c}\right)\right]}\right]\right\}\right]
\end{aligned}
$$

If we let

$$
\pi_{3}^{*}=1 / \pi_{3}
$$

then, it is easy to show that

$$
\begin{aligned}
& \Delta_{\mathrm{A}}^{*}=\left.\Delta_{\mathrm{A}}\right|_{\pi_{3} \rightarrow \pi_{3}^{*}}=\Delta_{\mathrm{B}} ; \Delta_{\mathrm{B}}^{*}=\left.\Delta_{\mathrm{B}}\right|_{\pi_{3} \rightarrow \pi_{3}^{*}}=\Delta_{\mathrm{A}} \\
& \Delta_{\mathrm{av}}^{*}=\left.\Delta_{\mathrm{av}}\right|_{\pi_{3} \rightarrow \pi_{3}^{*}}=\Delta_{\mathrm{av}} \\
& C_{t, \mathrm{av}}^{*}=\left.C_{t, \mathrm{av}}\right|_{\pi_{3} \rightarrow \pi_{3}^{*}}=C_{t, \mathrm{av}} ; C_{b, \mathrm{av}}^{*}=\left.C_{b, \mathrm{av}}\right|_{\pi_{3} \rightarrow \pi_{3}^{*}}=C_{b, \mathrm{av}}
\end{aligned}
$$

Consequently, we conclude that Eqs. (25) to (27) are symmetric around $\pi_{3}=1$ (i.e. $\omega_{\mathrm{A}}=\omega_{\mathrm{B}}$ ), and only the value for $\pi_{3} \leq 1$ need be considered.

\section{Optimal Position of the Barrier}

Equations (25) to (27) can be used to obtain the optimal position of the barrier for maximum degree of separation, maximum concentration of top product or minimum concentration of bottom product. Differentiating $\Delta_{\mathrm{av}}, C_{t, \mathrm{av}}$ or $C_{b, \mathrm{av}}$ with respect to the channel width ratio $\pi_{3}$ in Eqs. (25) to (27) and setting the derivatives to zero give the same necessary conditions for the optimal position of the barrier. The resultant equation is expressed in Eq. (34). For simplicity, the subscript "op" denoting optimum has been omitted.

$$
\begin{aligned}
5\left(\pi_{3}^{4}\right. & -1)\left(\pi_{3}^{2}-\pi_{3}+1\right)+\left[5\left(\pi_{3}^{2}-\pi_{3}+1\right)\right. \\
& +\left\{3\left(2 \pi_{3}^{2}-3 \pi_{3}+3\right)\left[1+\left(1+\pi_{3}\right)^{8}\left(1+\pi_{1} \pi_{2}\right)^{2}\left(K_{d} / K_{c}\right)\right]\right. \\
& \left.-8\left(1+\pi_{3}^{3}\right)\left(1+\pi_{3}^{3}\right)\left(1+\pi_{1} \pi_{2}\right)^{2}\left(1+\pi_{3}\right)^{7}\left(K_{d} / K_{c}\right)\right\} \\
& \times\left\{\frac{\sigma^{\prime} L^{\prime}\left(1+\pi_{1} \pi_{2}\right)^{2}\left(1+\pi_{3}\right)^{9}}{\left.\left.2\left(1+\pi_{3}^{3}\right)\left[1+\left(1+\pi_{1} \pi_{2}\right)^{2}\left(1+\pi_{3}\right)^{8}\left(K_{d} / K_{c}\right)\right]^{2}\right\}\right]}\right. \\
& \times \exp \left[\frac{-\sigma^{\prime} L\left(1+\pi_{3}\right)^{9}\left(1+\pi_{1} \pi_{2}\right)^{2}}{2\left(1+\pi_{3}^{3}\right)\left[1+\left(1+\pi_{1} \pi_{2}\right)^{2}\left(1+\pi_{3}\right)^{8}\left(K_{d} / K_{c}\right)\right]}\right] \\
= & {\left[5 \pi_{3}^{4}\left(\pi_{3}^{2}-\pi_{3}+1\right)+\left\{3\left(3 \pi_{3}^{2}-3 \pi_{3}+2\right)\right.\right.} \\
& \times\left[\pi_{3}^{8}+\left(1+\pi_{3}\right)^{8}\left(1+\pi_{1} \pi_{2}\right)^{2}\left(K_{d} / K_{c}\right)\right] \\
& \left.-8\left(1+\pi_{3}^{3}\right)\left(1+\pi_{1} \pi_{2}\right)^{2}\left(1+\pi_{3}\right)^{7}\left(K_{d} / K_{c}\right)\right\} \\
& \left.\times\left\{\frac{\sigma^{\prime} L^{\prime}\left(1+\pi_{1} \pi_{2}\right)^{2}\left(1+\pi_{3}\right)^{9} \pi_{3}^{6}}{2\left(1+\pi_{3}^{3}\right)\left[\pi_{3}^{8}+\left(1+\pi_{1} \pi_{2}\right)^{2}\left(1+\pi_{3}\right)^{8}\left(K_{d} / K_{c}\right)\right]^{2}}\right\}\right] \\
& \times \exp \left[\frac{-\sigma^{\prime} L^{\prime}\left(1+\pi_{3}\right)^{9}\left(1+\pi_{1} \pi_{2}\right)^{2} \pi_{3}^{2}}{2\left(1+\pi_{3}^{3}\right)\left[\pi_{3}^{8}+\left(1+\pi_{1} \pi_{2}\right)^{2}\left(1+\pi_{3}\right)^{8}\left(K_{d} / K_{c}\right)\right]}\right]
\end{aligned}
$$

It is easy to verify that the equation above is also symmetric around $\pi_{3}=1$. In general, the thermal conductivity of the barrier is much larger than that of the mixture. Accordingly, we may let $\left(1+\pi_{1} \pi_{2}\right) \cong 1$. The graphical solution of Eq. (34) has been calculated and is presented in Fig. 2 with $K_{c} / K_{d}$ as parameter. 


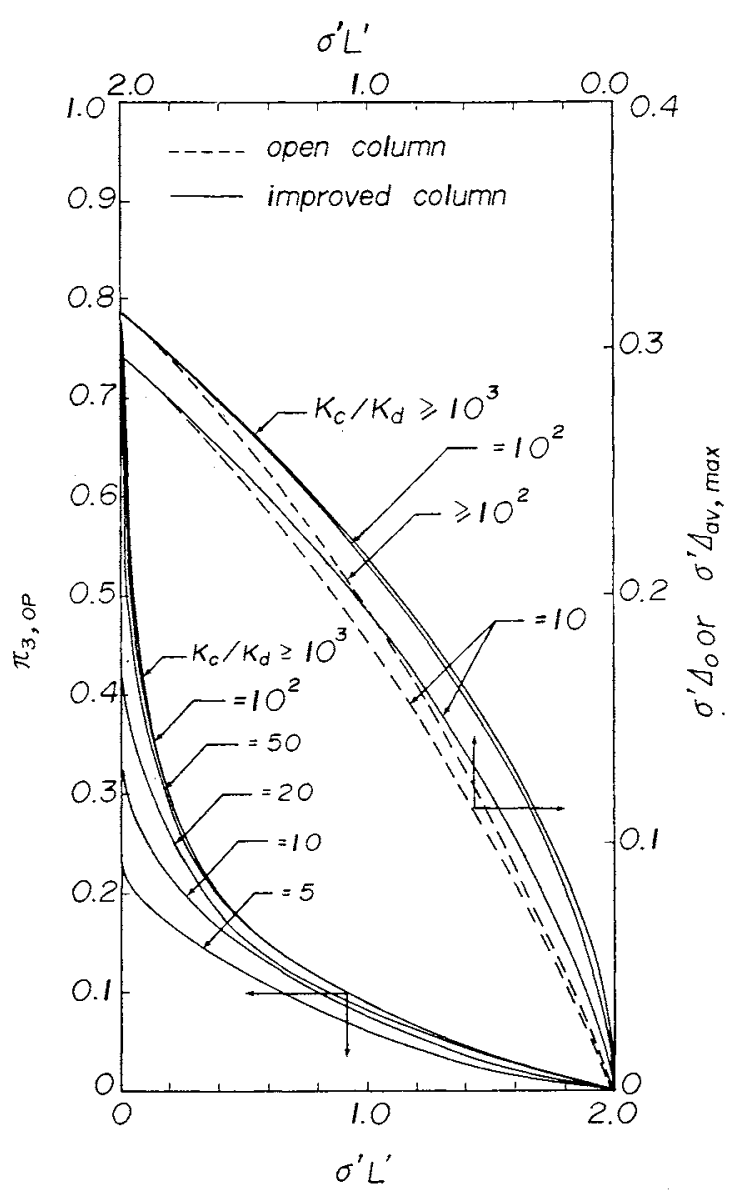

Fig. 2. Optimal position of barrier, product of dimensionless product rate and degree of separation at various $\sigma^{\prime} L^{\prime}$ with $K_{c} / K_{d}$ as parameter.

The products of maximum degree of separation and dimensionless flow rate for the open column and for the improved column, operated at optimal conditions, have been evaluated also and are presented in Fig. 2. For simplicity, only values with $\pi_{3} \leq 1$ are shown in the figure. Once the degree of separation is given, we may find $C_{t, \mathrm{av}}$ and $C_{b, \mathrm{av}}$ directly from Eqs. (26) and (27).

From Fig. 2, it is found that the optimal position of the barrier moves toward the hot wall as $\sigma^{\prime} L^{\prime}$ increases for all values of $K_{c} / K_{d}$. When the value of $\sigma^{\prime} L^{\prime}$ is greater than two, the barrier should be located at the hot or the cold wall, i.e. there is no need to introduce the barrier. This behavior is quite different from that of a batch-type barrier column, ${ }^{9}$ in which the optimal position of the barrier should be located at the center between the walls, i.e. $\pi_{3}=1$, for $K_{c} / K_{d} \geq 80$.

It is easy to verify from Eq. (1) that the degree of separation decreases sharply as the dimensionless product rate $\sigma^{\prime}$ increases from zero. Accordingly, one may conclude that the relative strength of the forced convection to the natural convection has a profound effect on the separation efficiency, and that reducing such relative strength may lead to improved separation. This is because for a given product rate and fixed temperature gradient between the walls the introduction of an impermeable barrier will substantially decrease both forced and natural convection strengths in each section. Therefore, properly adjusting the barrier position might effectively regulate the relative strength of convections in each section, and consequently leads to improved separation with fixed $L^{\prime}$ and temperature gradient (or heat consumption). It is concluded that when $\sigma^{\prime}$ increases, the only way to reduce the relative strength in each section is to move the barrier toward the hot plate (or cold plate if $\pi_{3}>1$ ).

\section{Improvement of Separation}

The improvement of separation by operating at the optimal condition is best illustrated by calculating the percentage increase in the degree of separation relative to the open column.

$$
I=\frac{\left(\Delta_{\mathrm{av}}\right)_{\max }-\Delta_{o}}{\Delta_{o}}
$$

Some results are presented in Fig. 3 with $K_{c} / K_{d}$ as the parameter. In addition, a numerical example for the separation of benzene and $n$-heptañe liquid mixture is given as follows. Some equipment parameters and physical properties of the mixture were found from Perry's Handbook as:

$$
\begin{aligned}
& B=10 \mathrm{~cm}, \quad g=980 \mathrm{~cm} / \mathrm{s}^{2}, \quad \omega_{\mathrm{A}}+\omega_{\mathrm{B}}=0.08 \mathrm{~cm}, \\
& \Delta T=42 \mathrm{~K}, \quad \tilde{T}=301 \mathrm{~K}, \quad \alpha=1.2, \\
& C_{f, \mathrm{~A}}=C_{f, \mathrm{~B}}=0.5 \quad \text { for benzene, } \\
& \mu=1.34 \times 10^{-4} \exp (1072 / \tilde{T})[\mathrm{g} / \mathrm{cm} \mathrm{s}], \\
& \beta=4.31 \times 10^{-2} /(550.5-\tilde{T})^{0.641}\left[\mathrm{~g} / \mathrm{cm}^{3} \cdot \mathrm{K}\right], \\
& \rho=5.788\left(0.181-1.635 \times 10^{-4} \tilde{T}\right)\left[\mathrm{g} / \mathrm{cm}^{3}\right], \\
& D=\left[2.47+4.65 \times 10^{-2}(\tilde{T}-298)\right] \times 10^{-5}\left[\mathrm{~cm}^{2} / \mathrm{s}\right] .
\end{aligned}
$$

Substituting these values into Eqs. (3) to (5) yields

$$
\begin{aligned}
& H=1.028 \times 10^{-2}[\mathrm{~g} / \mathrm{s}], \quad K_{c}=2.072[\mathrm{~g} \mathrm{~cm} / \mathrm{s}], \\
& K_{d}=1.663 \times 10^{-5}[\mathrm{~g} \mathrm{~cm} / \mathrm{s}]
\end{aligned}
$$

Some calculated results are presented in Table 1 with column length and mass flow rate as parameters.

\section{Discussion}

The equation for obtaining the optimal barrier position has been derived and is presented graphically in Fig. 2 with $K_{c} / K_{d}$ as the parameter. However, due to the symmetry of the equation around $\pi_{3}=1$, only values with $\pi_{3} \leq 1$ are considered. From the figure, it is found that as $\sigma^{\prime} L^{\prime}$ increases, the optimal barrier position will move toward the hot or the cold wall. 
Table 1. Comparison of degree of separation for open and improved columns with column length and mass fow rate as parameters

\begin{tabular}{|c|c|c|c|c|c|c|c|c|c|c|c|c|}
\hline \multirow[b]{2}{*}{$\begin{array}{c}\sigma \\
{[\mathrm{g} / \mathrm{s}]}\end{array}$} & \multicolumn{4}{|c|}{$L=80 \mathrm{~cm}$} & \multicolumn{4}{|c|}{$L=100 \mathrm{~cm}$} & \multicolumn{4}{|c|}{$L=120 \mathrm{~cm}$} \\
\hline & $\begin{array}{c}\Delta \\
{[\%]}\end{array}$ & $\pi_{3, \mathrm{op}}$ & $\begin{array}{c}\Delta_{\mathrm{av}, \max } \\
{[\%]}\end{array}$ & $\begin{array}{c}I \\
{[\%]}\end{array}$ & $\begin{array}{c}\Delta_{o} \\
{[\%]}\end{array}$ & $\pi_{3, \mathrm{op}}$ & $\begin{array}{c}\Delta_{\mathrm{av}, \max } \\
{[\%]}\end{array}$ & $\begin{array}{c}I \\
{[\%]}\end{array}$ & $\begin{array}{c}\Delta_{0} \\
{[\%]}\end{array}$ & $\pi_{3 . \mathrm{op}}$ & $\begin{array}{c}\Delta_{\mathrm{av} \text { max }} \\
{[\%]}\end{array}$ & $\begin{array}{c}I \\
{[\%]}\end{array}$ \\
\hline $5.0 \times 10^{-3}$ & 14.89 & 0.24 & 22.93 & 54 & 18.26 & 0.21 & 26.30 & 44 & 21.50 & 0.18 & 28.81 & 34 \\
\hline $8.33 \times 10^{-3}$ & 14.16 & 0.17 & 18.27 & 29 & 17.16 & 0.14 & 20.59 & 20 & 19.97 & 0.12 & 22.97 & 15 \\
\hline $1.33 \times 10^{-2}$ & 13.15 & 0.11 & 14.99 & 14 & 15.67 & 0.09 & 16.92 & 8 & 17.94 & 0.06 & 18.66 & 4 \\
\hline $1.67 \times 10^{-2}$ & 12.53 & 0.09 & 13.79 & 10 & 14.77 & 0.06 & 15.36 & 4 & 16.74 & 0.04 & 17.07 & 2 \\
\hline
\end{tabular}

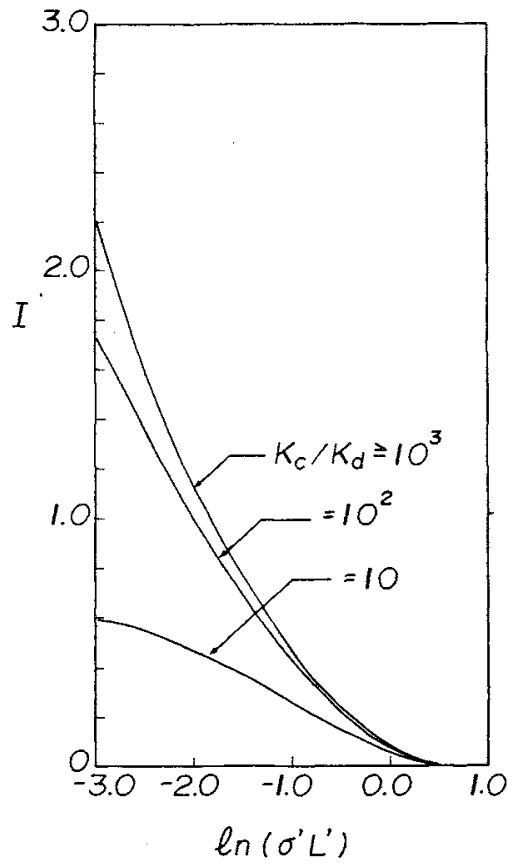

Fig. 3. Improvement of degree of separation relative to open column with $K_{d} / K_{d}$ as parameter.

Eventually, when the value of $\sigma^{\prime} L^{\prime}$ is greater than two, the barrier should be located at one of the walls, i.e. there is no need to introduce a barrier. We have also calculated the products of the dimensionless flow rate and the degree of separation for the open column and for the improved column operated at the optimal condition. The results are shown graphically in Fig. 2 with $K_{c} / K_{d}$ as parameter. It is found that $\pi_{3, o p}$ and $\sigma^{\prime} \Delta_{\mathrm{av}, \max }$ are insensitive to $K_{c} / K_{d}$ when its value exceeds one thousand. One can also find the optimal position of the barrier from Eq. (34) as the value of $K_{c} / K_{d}$ is smaller than one. However, this calculation is not essential because the value of $K_{c} / K_{d}$ is generally large, as shown in the numerical example for the separation of benzene and $n$-heptane liquid mixture. During the derivation of the equations above, the most important assumptions are that the concentration in the column is everywhere in the range $0.3 \leq C \leq 0.7$ and the products of physical properties in the transport constants are insensitive to the reference temperature. Modifications may be required when the above assumptions fail. ${ }^{8}$ Moreover, all the results obtained in this paper are valid only when the fluid in the column is in the laminar flow range.

\section{Conclusion}

It has been shown that the undesirable remixing effect in a flat-plate column can be effectively reduced by properly inserting a vertical impermeable barrier between the plates, thereby leading to improved separation with little increase, if any, in total cost. Basically, the degrees of separation for the improved columns reported in the literature have the same form as Eq. (1), except that the transport constants $H, K_{c}$ and $K_{d}$ are multiplied by modifying factors. ${ }^{19)}$ Consequently, the results obtained here can also be used in all those columns.

\section{Acknowledgement}

The authors wish to express their thanks to the Chinese National Science Council for financial aid.

\section{Nomenclature}

$B \quad=$ column width $\quad[\mathrm{cm}]$

C $=$ weight fraction of component 1 in binary mixtures

$C_{b}, C_{f}, C_{f}=C$ in bottom product, feed stream and top product, respectively

$D \quad=$ ordinary diffusion coefficient $\quad\left[\mathrm{cm}^{2} / \mathrm{s}\right]$

g $\quad$ gravitational acceleration $\quad\left[\mathrm{cm} / \mathrm{s}^{2}\right]$

$H \quad=$ transport constant defined by Eq. (3) $[\mathrm{g} / \mathrm{s}]$

$I \quad=$ improvement of separation defined by Eq. (35)

$J_{X-O D}, J_{X-T D}=$ mass flux of component 1 in horizontal direction due to ordinary and thermal diffusion, respectively $\left[\mathrm{g} / \mathrm{scm}^{2}\right]$

$J_{Z-O D}=$ mass flux of component 1 in vertical direction due to diffusion

$K_{c}, K_{d} \quad=$ transport constants defined by Eqs. (4) and (5), respectively

$[\mathrm{gcm} / \mathrm{s}$ ]

$k, k_{1}=$ thermal conductivities for mixture and barrier respectively

$[\mathrm{cal} / \mathrm{cm} \mathrm{s} \cdot \mathrm{K}$ ]

$L \quad=$ column length $\quad[\mathrm{cm}]$

$\left.\begin{array}{lll}\widetilde{T} & =\text { reference temperature }\end{array}\right]$

$T_{m} \quad=$ arithmetic mean temperature $\quad[\mathrm{K}]$

$T_{1}, T_{2} \quad=$ temperatures of the cold and hot plates respectively

$\Delta T=$ difference in temperature of hot and cold plates

$\alpha \quad=$ thermal diffusion constant $\quad[-]$ 


\begin{tabular}{|c|c|}
\hline$\beta$ & $=$ thermal expansion coefficient defined as \\
\hline & $\begin{aligned} & -(\partial \rho / \partial T) \quad\left[\mathrm{g} / \mathrm{cm}^{3} \cdot \mathrm{K}\right] \\
= & \text { degree of separation defined by concentration }\end{aligned}$ \\
\hline$\Delta$ & $\begin{aligned}= & \text { degree of separation defined by concentration } \\
& \text { difference between top and bottom products }\end{aligned}$ \\
\hline$\delta$ & $=$ thickness of barrier $\quad[\mathrm{cm}]$ \\
\hline$\mu$ & $=$ viscosity of mixture $\quad[\mathrm{g} / \mathrm{cm} \mathrm{s}]$ \\
\hline$\pi_{1}, \pi_{2}, \pi_{3}$ & $\begin{array}{l}=\text { dimensionless groups defined by Eqs. (22), (23) } \\
\text { and (24) }\end{array}$ \\
\hline$\rho$ & $=$ density of mixture \\
\hline$\sigma$ & $=$ mass flow rate of top or bottom product \\
\hline & $=$ thickness of section \\
\hline
\end{tabular}

〈Superscripts and Subscripts〉

$\begin{array}{ll}* & =\text { defined for } \pi_{3} \text { by Eq. (30) } \\ \text { A } & =\text { dimensionless groups defined in Eq. (2) } \\ \text { B } & =\text { refer to section A } \\ o & =\text { refer to section B } \\ \text { av } & =\text { average column } \\ \text { op } & =\text { at optimal conditions defined in Eq. (19) to (21) } \\ \max & =\text { maximum value at optimal condition }\end{array}$

\section{Literature Cited}

1) Chueh, P. L. and H. M. Yeh: AIChE J., 13, 37 (1967).

2) Clusius, K. and G. Dickel: Naturwissenschaften, 26, 546L (1938).

3) Furry, W. H., R. C. Jones and L. Onsager: Phys. Rev., 55, 1083 (1939).
4) Lorenz, M. and A. H. Emery, Jr.: Chem. Eng. Sci., 11, 16 (1959).

5) Power, J. E. and C. R. Wilke: AIChE J., 3, 213 (1957).

6) Ramser, J. H.: Ind. Eng. Chem., 49, 155 (1957).

7) Sullivan, L. J., T. C. Ruppel and C. B. Willingham: Ind. Eng. Chem., 49, 110 (1957).

8) Tsai, S. W. and H. M. Yeh: Sep. Sci. Technol., 19, 497 (1984).

9) Tsai, S. W. and H. M. Yeh: Ind. Eng. Chem. Fundam., 25, 367 (1986).

10) Washall, T. A. and F. W. Molpolder: Ind. Eng. Chem., Process Des. Dey, 1, 26 (1962).

11) Yeh, H. M. and H. C. Ward: Chem. Eng. Sci., 26, 937 (1971).

12) Yeh, H. M. and C. S. Tsai: Chem. Eng. Sci., 27, 2065 (1972).

13) Yeh, H. M. and S. M. Cheng: Chem. Eng. Sci., 28, 1803 (1973).

14) Yeh, H. M. and T. Y. Chu: Chem. Eng. Sci., 29, 1421 (1974).

15) Yeh, H. M. and F. K. Ho: Chem. Eng. Sci, 30, 1381 (1975).

16) Yeh, H. M. and S. W. Tsai: J. Chem. Eng. Japan, 14, 90 (1981).

17) Yeh, H. M. and S. W. Tsai: Sep. Sci. Technol., 16, 63 (1981).

18) Yeh, H. M. and S. W. Tsai: Sep. Sci. Technol., 17, 1075 (1982).

19) Yeh, H. M. and Y. T. Yeh: Chem. Eng. J., 25, 55 (1982).

20) Yeh, H. M. and S. W. Tsai: Can. J. Chem. Eng., 63, 406 (1985).

21) Yeh, H. M., S. W. Tsai and C. S. Lin: AlChE J., 32, 971 (1986).

22) Yeh, H. M., S. W. Tsai and W. H. Chen: Can. J. Chem. Eng., (in press). 